\title{
Retraction Note to: Automatic Segmentation of Brain MRI of Newborn and Premature Infants Using Neural Network
}

Tushar H. Jaware, K.B. Khanchandani and Anita Zurani

\author{
Retraction Note to: \\ "Automatic Segmentation of Brain MRI of Newborn \\ and Premature Infants Using Neural Network" in: R. Singh \\ and S. Choudhury (eds.), Proceeding of International \\ Conference on Intelligent Communication, Control \\ and Devices, Advances in Intelligent Systems \\ and Computing 479, \\ DOI 10.1007/978-981-10-1708-7_89
}

The authors have retracted this conference paper published in Proceeding of International Conference on Intelligent Communication, Control and Devices, Vol. 479, Advances in Intelligent Systems and Computing, pp. 771-777 , Sept. 2016, 10.1007/978-981-10-1708-7_89 because it contains large portions of text in the "Introduction Section" that have been duplicated from another article previously published in Computers in Biology and Medicine, Volume 64, Issue September 2015, pages 163-178, http://dx.doi.org/10.1016/j.compbiomed.2015.06.016 by Chelli N. Devi, Anupama Chandrasekharan, V. K. Sundararaman, Zachariah C. Alex. The authors apologize to the Editors and readers as well as the authors of the original article. Retraction does not affect the major conclusions of the chapter.

The retracted online version of this chapter can be found at http://dx.doi.org/10.1007/978-981-10-1708-7_89 